\title{
Palladate Salts from Ionic Liquids as Catalysts in the Heck Reaction
}

\author{
Florence Gayet, Jean-Daniel Marty and Nancy Lauth-de Viguerie* \\ Université de Toulouse; UPS; IMRCP; 118 route de Narbonne, F-31062 Toulouse Cedex 9, \\ France CNRS; IMRCP; F-31062 Toulouse, France \\ Email:viquerie@chimie.ups-tlse.fr
}

\begin{abstract}
Palladate salts from imidazolium and pyridinium ionic liquids (ILs) were used as catalysts in Heck reaction. When compared to traditional precatalysts, they demonstrated to be more efficient catalysts. These results are attributed to the presence of nanoparticles (NPs) which served as a reservoir of palladium species. Indeed the use of palladate salts from ILs, that produce no byproducts, provide better control of the formation and surface composition of the NPs leading to a constant recyclability.
\end{abstract}

Keywords: Ionic Liquids nanoparticles Heck reaction recycling

\section{Introduction}

The Heck reaction is one of the most important methods in synthetic organic chemistry for the formation of $\mathrm{C}-\mathrm{C}$ bonds. ${ }^{1,2}$ The reaction is frequently catalysed by palladium catalysts in the presence of a phosphine and a base at high temperatures. A large variety of $\operatorname{Pd}(\mathrm{II})$ and $\operatorname{Pd}(0)$ complexes, among which $\mathrm{Pd}(\mathrm{OAc})_{2}, \mathrm{Pd}_{2}(\mathrm{dba})_{3}$ are the most commonly used, can serve as effective precatalysts, or precursors to the active $\mathrm{Pd}(0)$ catalyst.

Polar aprotic solvents such as DMF and $\mathrm{CH}_{3} \mathrm{CN}$ are the most commonly used solvents in this reaction. Replacement of these traditional but toxic organic solvents by so-called green solvents (supercritical fluids, ${ }^{3,4}$ perfluorinated solvents ${ }^{5}$ or $\mathrm{ILs}^{6,7}$ ) has been the object of numerous studies. ILs are of special interest due to their specific properties: they present good chemical and thermal stability, low vapour pressure, wide liquid range, good solubility for a wide range of organic and inorganic reagents and they allow the facile separation of the products and recycling of the ILs containing the catalysts. ${ }^{8,9}$ In addition to this, the use of ILs in the Heck reaction has opened new insights and perspectives: ${ }^{10}$ (i) ILs containing imidazolium cations stabilize ligandfree precursors of catalysts (free of $\eta^{2}$ donor ligands such as phosphines), consequently catalysts like palladium acetate proved to be efficient even at low concentrations and have been widely used; ${ }^{8,11,12}$ (ii) When performed in ILs, the reaction rate was significantly increased. ${ }^{13-15}$ In 
certain cases, this enabled the regioselectivity of the products obtained to be controlled; ${ }^{16}$ (iii) The involvement of Pd nanoparticles (Pd NPs) as a reservoir of molecular palladium species, as proposed by Dupont ${ }^{17}$ and in agreement with the results obtained by de Vries ${ }^{18}$ has received abundant experimental support especially in the case of ligand-free palladium catalysts. ${ }^{17,19}$ However, the precise nature of the reactive species in the catalytic cycle is not well defined. In order to develop systems that minimize the formation of chemical by-products, the use of metalcontaining ILs that only generate IL moieties in the media, could be of special interest. ${ }^{20}$ Moreover, such precursors should permit, especially when NPs are involved, a better control of the surface chemistry of the active species with IL species bonded to the NP surfaces. Hence, Itoh et al. ${ }^{21}$ have shown that when gold NPs were bound to ILs, the hydrophobic and hydrophilic properties of the NPs can be tuned by exchanging the anions of the IL moiety.

Herein we report use of two palladate salts synthesized from imidazolium and pyridinium ILs in IL 1-butyl-3-methylimidazolium hexafluorophosphate $\left(\mathrm{BmimPF}_{6}\right)$ in a well-known Heck C-C coupling reaction between iodobenzene and styrene, chosen as a model reaction. The catalytic activity and recyclability of these catalytic species were compared to those of commercial palladium catalysts.

\section{Results and Discussion}

\section{Precatalyst formation and characterisation.}

Two palladium-containing IL catalysts (Figure 1) were generated from palladium chloride $\mathrm{PdCl}_{2}$ and the appropriate IL. Bis(1-butyl-3-methylimidazolium) tetrachloropalladate noted $[\mathrm{Bmim}]_{2}\left[\mathrm{PdCl}_{4}\right]$ was synthesized according to a procedure described by Dupont et al. ${ }^{22}$ and each pure stereoisomers and racemate of bis(1-phenylethylpyridinium) tetrachloropalladate $[\mathrm{Pyr}]_{2}\left[\mathrm{PdCl}_{4}\right]$ were prepared as previously described in quantitative yield by reacting palladium chloride with a 2-molar excess of the $(R)-,(S)$ - and (rac)-1-phenylethylpyridinium chloride respectively in acetonitrile for 24 hours under reflux. ${ }^{13,23}\left[\mathrm{Pyr}_{2}\left[\mathrm{PdCl}_{4}\right]\right.$ and $[\mathrm{Bmim}]_{2}\left[\mathrm{PdCl}_{4}\right]$ are obtained as light brown and yellow-orange monocrystals respectively with crystal X-ray structures described in literature. ${ }^{22,23}$ Their melting points were $155{ }^{\circ} \mathrm{C}$ and $125{ }^{\circ} \mathrm{C}$ respectively. Moreover, the upper limits of the liquidus range of these salts which is bounded by thermal decomposition were also determined at $210{ }^{\circ} \mathrm{C}$ and upon $230^{\circ} \mathrm{C}$ respectively. So, these two salts are thermally stable in the conditions of the Heck reaction. 


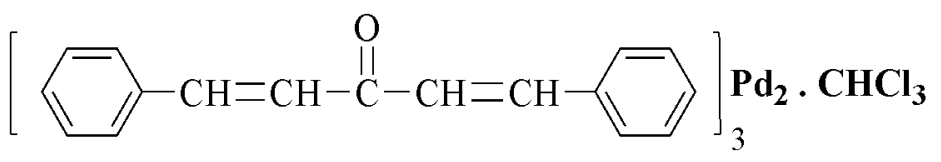

$\mathrm{Pd}_{2}(\mathrm{dba})_{3} \cdot \mathrm{CHCl}_{3}$

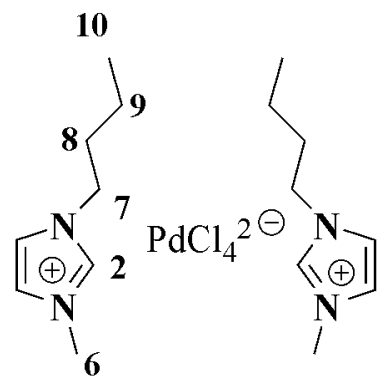

$[\mathrm{Bmim}]_{2}\left[\mathrm{PdCl}_{4}\right]$

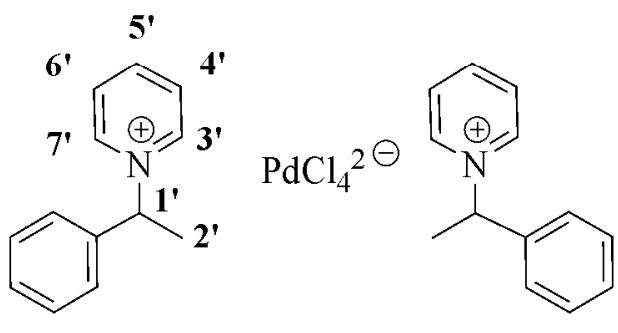

$[\mathrm{Pyr}]_{2}\left[\mathrm{PdCl}_{4}\right]$

Figure 1. Palladium catalysts used.

\section{Heck reaction with ionic salts in ionic liquids.}

Heck cross-coupling between iodobenzene and styrene was performed in $\mathrm{BmimPF}_{6}$ at $100^{\circ} \mathrm{C}$ using one of these palladium derivatives ( $1 \mathrm{~mol} \%$ relative to the halide) as catalyst and $\mathrm{Et}_{3} \mathrm{~N}$ as base (Figure 2).

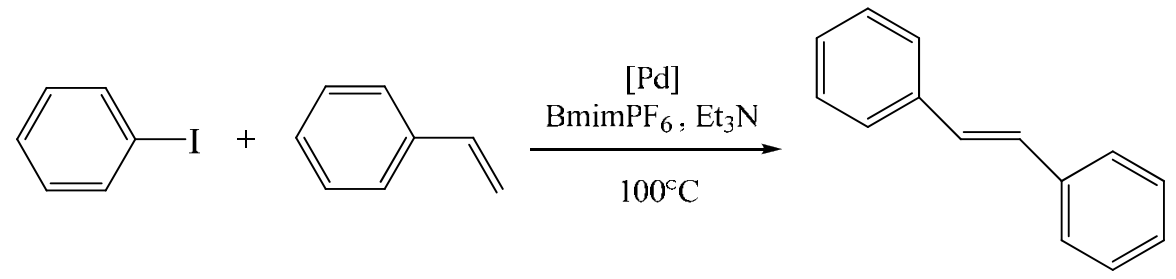

Figure 2. Heck cross-coupling reaction of iodobenzene with styrene in the presence of various catalysts: $\mathrm{Pd}(\mathrm{OAc})_{2}, \mathrm{Pd}_{2}(\mathrm{dba})_{3} . \mathrm{CHCl}_{3},[\mathrm{Bmim}]_{2}\left[\mathrm{PdCl}_{4}\right]$ and $[\mathrm{Pyr}]_{2}\left[\mathrm{PdCl}_{4}\right]$ racemate.

Two commercial catalysts: palladium acetate $\mathrm{Pd}(\mathrm{OAc})_{2}$ and tris(dibenzylideneacetone) dipalladium(0) chloroform adduct $\mathrm{Pd}_{2}(\mathrm{dba})_{3} \cdot \mathrm{CHCl}_{3}$ were also used for comparison purposes. $\mathrm{BmimPF}_{6}$ was chosen as solvent due to its particular properties: whereas the different catalysts and reactants are perfectly soluble in $\mathrm{BmimPF}_{6}$, its immiscibility with diethylether and water allowed respectively the easy extraction of reaction products and the elimination of the amine hydrochloride. Hence, iodobenzene, styrene and the reaction products were quantitatively and selectively extracted from the IL solution by diethylether (see experimental section).

In a first set of experiments, the conversion of iodobenzene and the reaction yield were evaluated by HPLC (see experimental section) and followed versus time. No residual peaks from 
ionic liquids, catalysts or base were observed on the chromatograms. The results obtained are summarized in Table 1.

Table 1. Heck Cross-Coupling Reaction of Iodobenzene with Styrene in the presence of various catalysts in $\mathrm{BmimPF}_{6}$ at different reaction times ${ }^{\mathrm{a}}$.

\begin{tabular}{lllllllllll}
\hline Catalyst & $\mathrm{Pd}(\mathrm{OAc})_{2}$ & $\mathrm{Pd}_{2}(\mathrm{dba})_{3}$ & \multicolumn{4}{c}{$[\mathrm{Bmim}]_{2}\left[\mathrm{PdCl}_{4}\right]$} & \multicolumn{4}{c}{$[\mathrm{Pyr}]_{2}\left[\mathrm{PdCl}_{4}\right]$} \\
\hline Time $^{\mathrm{a}}$ & $6 \mathrm{~h}$ & $1 \mathrm{~h}$ & $3 \mathrm{~h}$ & $6 \mathrm{~h}$ & $1 \mathrm{~h}$ & $3 \mathrm{~h}$ & $6 \mathrm{~h}$ & $1 \mathrm{~h}$ & $3 \mathrm{~h}$ & $6 \mathrm{~h}$ \\
Conversion(\%) $^{\mathrm{b}}$ & 89 & 41 & 77 & 98 & 30 & 84 & 99 & 67 & 88 & 99 \\
Yield (\%) $^{\mathrm{c}}$ & 87 & 39 & 73 & 95 & 29 & 83 & 96 & 60 & 86 & 97 \\
\hline
\end{tabular}

${ }^{a}$ All reactions were carried out using $1 \mathrm{mmol}$ of iodobenzene, $1.2 \mathrm{mmol}$ of styrene, $1.5 \mathrm{mmol}$ of $\mathrm{Et}_{3} \mathrm{~N}, 1 \mathrm{~mol} \%$ catalyst relative to iodobenzene, and $0.5 \mathrm{~g}$ of $\mathrm{BmimPF}_{6}$ at $100^{\circ} \mathrm{C}$. ${ }^{\mathrm{b}}$ Conversion of iodobenzene determined by HPLC of the diethylether phase. ${ }^{\mathrm{c}}$ Trans-stilbene yield determined by HPLC of the diethylether phase.

In all cases, the reaction was regiospecific and the only product formed was trans-stilbene, as confirmed by ${ }^{1} \mathrm{H}$ NMR and HPLC analysis (see supplementary material). The conversion ratio of iodobenzene after $6 \mathrm{~h}$ was $98-99 \%$ except in the case of $\mathrm{Pd}(\mathrm{OAc})_{2}(89 \%)$. The same reaction performed in DMF led to trans-stilbene as the only product with a conversion ratio of $56 \%$ after $6 \mathrm{~h}$. As expected from literature results, ${ }^{13-15,24}$ the rate of reaction was significantly increased when performed in ILs. In all cases, the remaining IL catalytic system was a purple homogeneous solution and no black palladium deposits were detected.

\section{Catalyst Recycling in the Heck reaction.}

The activity and potential reuse of the three catalysts dissolved in $\mathrm{BmimPF}_{6}$ was then studied (six runs). In order to compare the different catalysts, we chose to quench the reaction and fixed the reaction time at 3 hours. A typical experiment consisted of running the Heck reaction and, after extraction of the reaction products with diethylether, the reaction vial was loaded with fresh styrene, iodobenzene and triethylamine for a new run. The catalytic recycling results are summarized in Figure 3. 


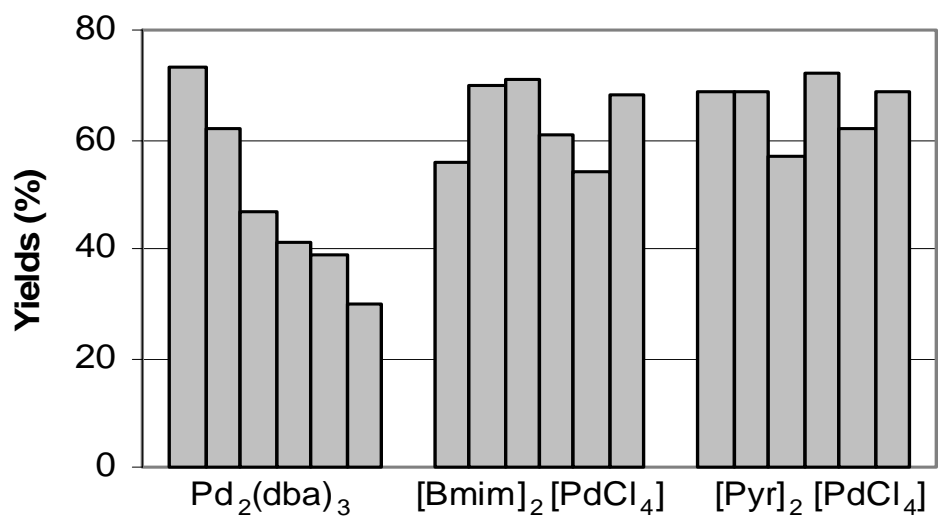

Figure 3. Recyclability during the first six runs of the different catalysts $(1 \mathrm{~mol} \%)$ in the Heck reaction between iodobenzene $(1 \mathrm{mmol})$ and styrene $(1.2 \mathrm{mmol})$ in $\mathrm{BmimBF}_{6}$ stopped after 3 hours of reaction. Trans-stilbene yields (\%) were obtained from HPLC measurements (see experimental part).

After completion of the sixth cycle, no significant difference between $[\mathrm{Bmim}]_{2}\left[\mathrm{PdCl}_{4}\right]$ and $[\mathrm{Pyr}]_{2}\left[\mathrm{PdCl}_{4}\right]$ was seen in catalytic results. In contrast, $\mathrm{Pd}_{2}(\mathrm{dba})_{3}$ led to a significant decrease of catalytic activity. To better understand this evolution, TEM analysis of the remaining IL phase was performed after each cycle for all catalysts. Since ILs have no measurable vapour pressure, TEM analysis can be carried out in situ. ${ }^{17}$ In all cases, the formation of Pd NPs was confirmed after the first catalysis cycle. Whereas, with $\mathrm{Pd}_{2}(\mathrm{dba})_{3}, \mathrm{Pd}$ NPs presented a polydisperse size distribution with rather small NPs (Figure 4a) and large clusters (see supplementary material), the two other catalysts led to Pd NPs with very few large clusters (Figures $4 \mathrm{~b}$ and $4 \mathrm{c}$ ). 

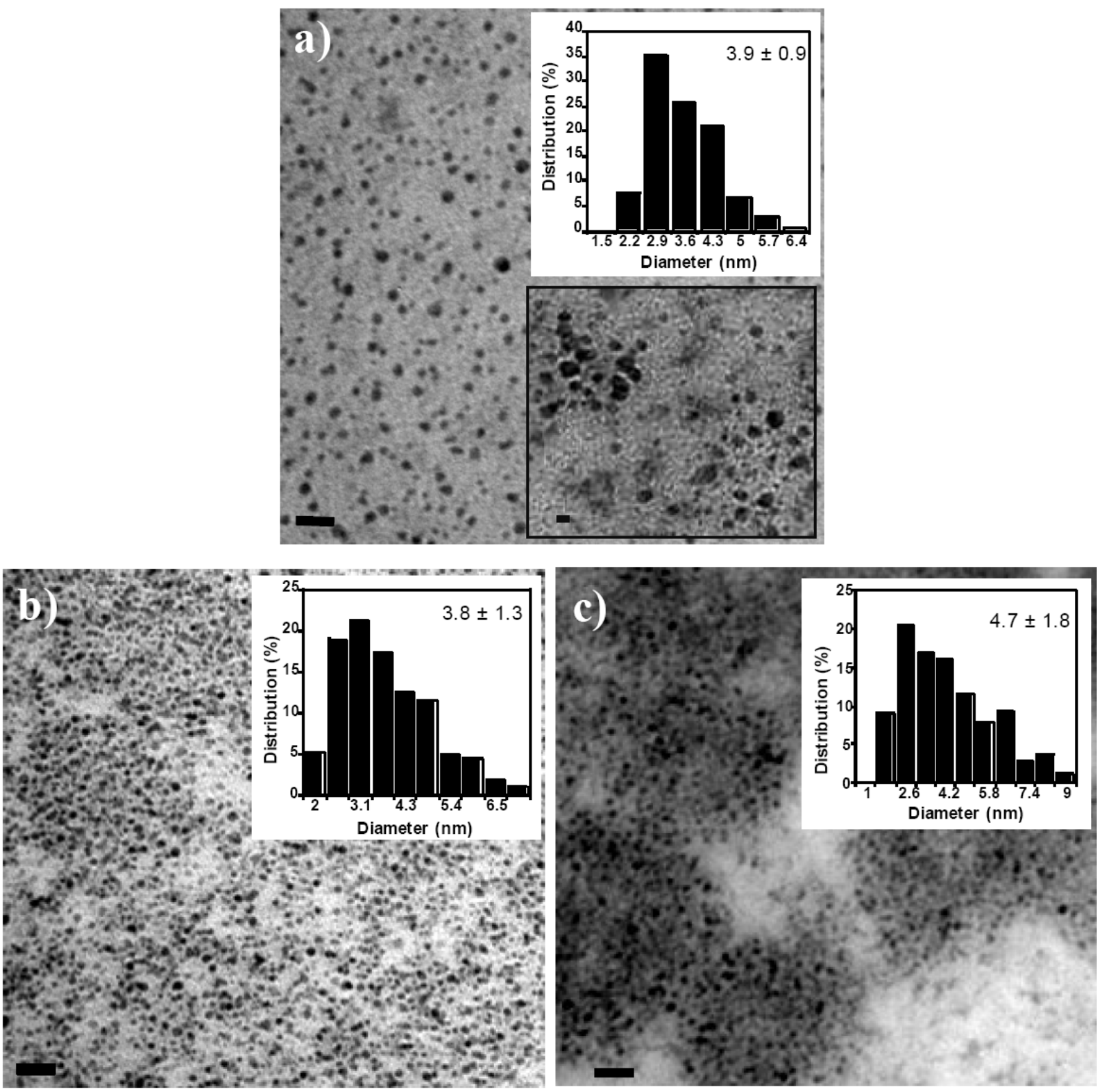

Figure 4. TEM micrographs and corresponding histograms (at least 270 nanoparticles analyzed) illustrating the palladium nanoparticle diameter distribution after six cycles for the reaction catalyzed by (a) $\mathrm{Pd}_{2}(\mathrm{dba})_{3}$ (b) $[\mathrm{Bmim}]_{2}\left[\mathrm{PdCl}_{4}\right]$ (c) $[\mathrm{Pyr}]_{2}\left[\mathrm{PdCl}_{4}\right]$. The scale bars represent $25 \mathrm{~nm}$.

These NPs remain stable and active during recycling experiments and no significant evolution was observed during recycling experiments concerning size distribution. After recovery, the reaction medium was still active after six months' storage. A summary of the sizes obtained after the last run of the catalyst recycling experiment is given in Table 2 . 
Table 2. TEM analysis of the catalyst solutions giving mean diameter ${ }^{\mathrm{a}}$, median ${ }^{\mathrm{a}}$, standard deviation ${ }^{\mathrm{a}}$ and existence of large clusters.

\begin{tabular}{|c|c|c|c|}
\hline \multirow[t]{2}{*}{ Catalyst } & $\begin{array}{l}\text { Mean Diameter }(\mathrm{nm}) \\
\pm \text { Standart deviation }(\mathrm{nm}) \\
(\text { Median in } \mathrm{nm})\end{array}$ & \multicolumn{2}{|c|}{ Existence of large clusters } \\
\hline & Before reaction & After reaction & \\
\hline $\mathrm{Pd}_{2}(\mathrm{dba})_{3}$ & 1 & $\begin{array}{l}3.9 \pm 0.9^{\mathrm{b}} \\
(3.8)\end{array}$ & Yes $(>25 \mathrm{~nm})$ \\
\hline$[\mathrm{Bmim}]_{2}\left[\mathrm{PdCl}_{4}\right]$ & l & $\begin{array}{l}3.8 \pm 1.3^{b} \\
(3.6)\end{array}$ & No \\
\hline$[\mathrm{Pyr}]_{2}\left[\mathrm{PdCl}_{4}\right]$ & l & $\begin{array}{l}4.7 \pm 1.8^{b} \\
(4.4)\end{array}$ & No \\
\hline $\begin{array}{l}{[\mathrm{Bmim}]_{2}\left[\mathrm{PdCl}_{4}\right]} \\
\text { reduced }\end{array}$ & $\begin{array}{l}4.3 \pm 2.1 \\
(3.5)\end{array}$ & $\begin{array}{l}2.4 \pm 0.6^{\mathrm{c}} \\
(2.3)\end{array}$ & No \\
\hline $\begin{array}{l}{[\mathrm{Pyr}]_{2}\left[\mathrm{PdCl}_{4}\right]} \\
\text { reduced }\end{array}$ & $\begin{array}{l}3.8 \pm 3.4 \\
(2.2)\end{array}$ & $\begin{array}{l}2.0 \pm 0.2^{\mathrm{c}} \\
(1.9)\end{array}$ & No \\
\hline
\end{tabular}

${ }^{a}$ Determined thanks to ImageJ software. ${ }^{b}$ Determined after the sixth run.

${ }^{\mathrm{c}}$ Determined after the first catalysis experiment

As described in the literature, ${ }^{17,18,25}$ it is now generally accepted that Pd NPs can act as reservoirs of Pd molecular species and leach active molecular species in the Heck coupling reaction. The large Pd NPs clusters formed when $\operatorname{Pd}_{2}\left(\mathrm{dba}_{3}\right.$ was used as catalyst could account for the significant decrease of the catalytic activity. In contrast, $[\mathrm{Bmim}]_{2}\left[\mathrm{PdCl}_{4}\right]$ and $[\mathrm{Pyr}]_{2}\left[\mathrm{PdCl}_{4}\right]$ gave a better control of NP formation and allowed the leaching mechanism to be more effective by avoiding the formation of large clusters. Moreover, Pd catalytic efficiency was greatly improved upon lowering of Pd load: for instance, with $[\mathrm{Bmim}]_{2}\left[\mathrm{PdCl}_{4}\right]$ the trans-stilbene yield decrease by an half on increasing Pd loading from $0.03 \mathrm{~mol} \%$ to $1 \mathrm{~mol} \%$. This was in good agreement with the existence of an equilibrium between Pd NPs serving as catalyst reservoirs and small catalytically active species. When the catalyst concentration is high, inactive Pd black forms in larger quantities. ${ }^{19}$ This result also agrees with the results obtained from kinetic studies showing the existence of a "critical" $\operatorname{Pd}(0)$ concentration and a "critical" formation rate of the catalytic species. ${ }^{26}$ 


\section{Nature of the true catalyst.}

Several experiments were performed to better understand the true nature of the catalytic species. First to check involvement of any carbene chemical species, palladium catalyst $\left([\mathrm{Bmim}]_{2}\left[\mathrm{PdCl}_{4}\right]\right.$, $[\mathrm{Pyr}]_{2}\left[\mathrm{PdCl}_{4}\right]$ ) and $\mathrm{BmimPF}_{6}$ were mixed and analysed by ${ }^{1} \mathrm{H}$ and ${ }^{13} \mathrm{C} \mathrm{NMR}$ techniques in deuterated dichloromethane. In all the cases, no carbene palladium complex was formed. This result discard the possibility to form Pd NPs from carbene intermediates, but the formation of carbene species at the metal surface could not be excluded. Then, to demonstrate the precise role of NPs (catalytic species or reservoirs of Pd molecular species) we formed, prior to reaction, $\mathrm{Pd}$ NPs by reduction of the palladium (II) catalyst $\left([\mathrm{Bmim}]_{2}\left[\mathrm{PdCl}_{4}\right]\right.$ or $\left.[\mathrm{Pyr}]_{2}\left[\mathrm{PdCl}_{4}\right]\right)$ by an excess of sodium borohydride. The preformed NPs were observed by TEM (Figure 5) and have an average size of 4.3 and $3.8 \mathrm{~nm}$ respectively. After reaction, a slight decrease in the mean average size was observed, whereas the median evolved to a lesser extent which could indicate the disappearance of the larger clusters.
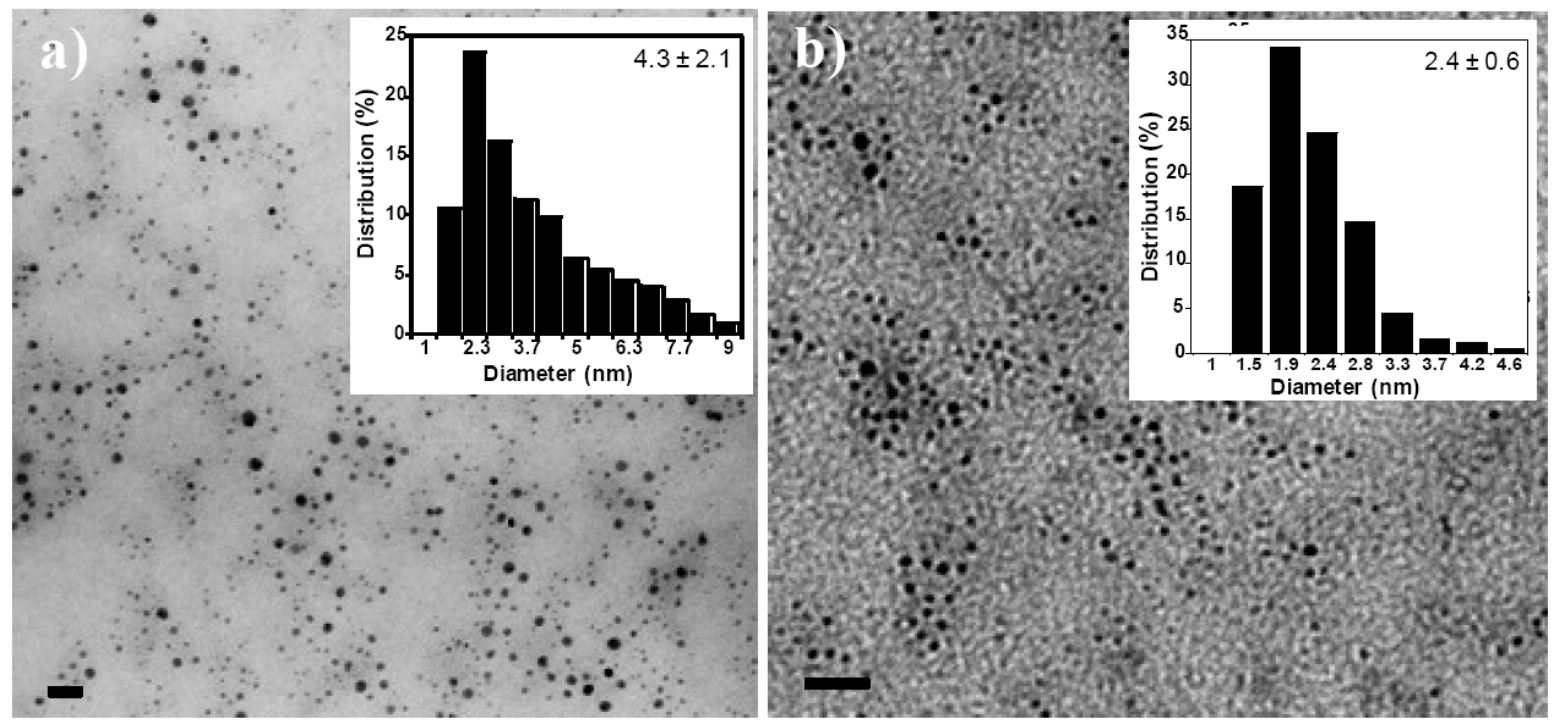

Figure 5. TEM micrographs and corresponding histograms (at least 430 nanoparticles analyzed) illustrating the palladium nanoparticle diameter distribution obtained from reduced $[\mathrm{Bmim}]_{2}\left[\mathrm{PdCl}_{4}\right]$ using $\mathrm{NaBH}_{4}$ (a) before reaction; (b) after reaction. The scale bars represent 25 nm.

The conversion ratio of iodobenzene obtained with these preformed NPs from $[\mathrm{Bmim}]_{2}\left[\mathrm{PdCl}_{4}\right]$ and $[\mathrm{Pyr}]_{2}\left[\mathrm{PdCl}_{4}\right]$ were found equal to $85 \%$ and $82 \%$ respectively after 3 hours of reaction. These results were comparable to the one obtained using non reduced palladate salts $(84 \%$ and $88 \%)$. As in the former case NPs are significatively smaller (twice) and so have a larger surface available for the catalytical process this suggest that the NPs act only as reservoirs for smaller catalytical species. This was in good agreement with the results of Köhler and col. that have demonstrated clearly a correlation between palladium content in solution and 
reaction rate. ${ }^{27}$ To confirm this, we perform Heck reaction with the residual compounds obtained after extraction with diethylether of the IL phase containing NPs. This extracted phase (containing no NPs) proved to be effective in Heck reaction. All these results clearly demonstrate the crucial role of leaching during Heck reaction; nevertheless, the precise nature of the active species has not been clearly identified.

\section{Heck reaction between iodobenzene with 2,3-dihydrofurane.}

As we had each enantiomer of $[\mathrm{Pyr}]_{2}\left[\mathrm{PdCl}_{4}\right](R, R-$ or $S, S-\mathrm{Pyr})$, we tried to evaluate the effect of a chiral catalyst on a asymmetric Heck coupling reaction. So, we replaced styrene by 2,3dihydrofuran ${ }^{11}$ and performed the reaction in similar conditions as those previously described.

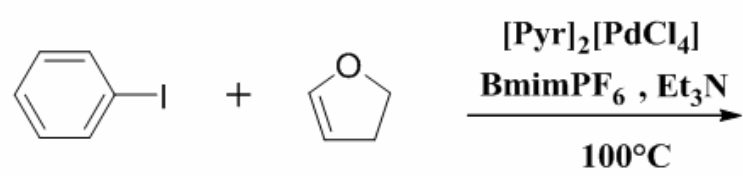

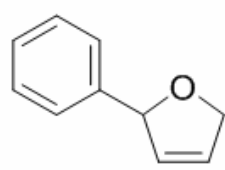

(A)

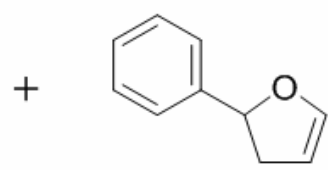

(B)

Figure 6. Heck cross-coupling reaction of iodobenzene with 2,3-dihydrofurane in the presence of each enantiomer of $[\mathrm{Pyr}]_{2}\left[\mathrm{PdCl}_{4}\right](R, R-$ or $S, S-\mathrm{Pyr})$.

We observed only the regiospecific formation of compound (A) and the analysis (NMR, GC) were in agreement with those described in the literature. ${ }^{28}$ Whatever the initial chirality of the catalyst, no enantiomeric excess was detected by chiral GC.

\section{Potential exchange of $\left[\mathrm{Pyr}_{2}\left[\mathrm{PdCl}_{4}\right]\right.$ ions with those of $\mathrm{BmimPF}_{6}$ : studies by ${ }^{1} \mathrm{H} \mathrm{NMR}$ and FTIR.}

The absence of an enantiomeric excess and the comparable activities of $\left[\mathrm{Bmim}_{2}\left[\mathrm{PdCl}_{4}\right]\right.$ and $[\mathrm{Pyr}]_{2}\left[\mathrm{PdCl}_{4}\right]$ could be attributed to an exchange between the cations of catalyst and of $\mathrm{BmimPF}_{6}$. So studies by ${ }^{1} \mathrm{H}$ NMR and by FTIR were performed. Any exchange would lead, in the case of $[\mathrm{Pyr}]_{2}\left[\mathrm{PdCl}_{4}\right]$, to the formation of $\mathrm{PyrPF}_{6}$ and $[\mathrm{Bmim}]_{2}\left[\mathrm{PdCl}_{4}\right]$ as the active catalyst. In a first set of experiments the chemical shift change of the protons of the cation moiety was followed versus the molar fraction $\mathrm{r}=[\mathrm{Pyr}]_{2}\left[\mathrm{PdCl}_{4}\right] /\left([\mathrm{Pyr}]_{2}\left[\mathrm{PdCl}_{4}\right]+\mathrm{BmimPF}_{6}\right)$ by ${ }^{1} \mathrm{H} \mathrm{NMR}$ in deuterated dichloromethane. The results are summarized in Figure 7 (see supplementary material for corresponding spectra). 


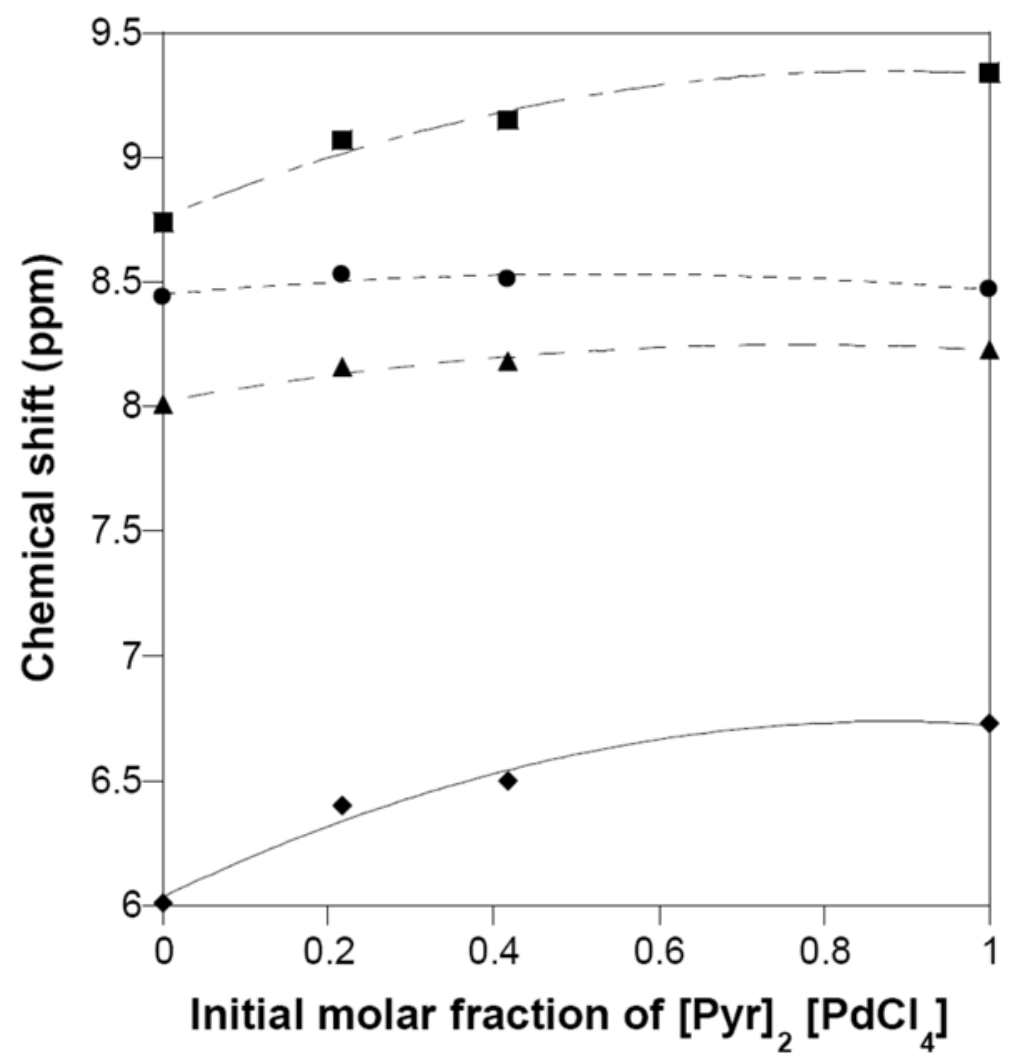

Figure 7. Chemical shifts of the pyridinium cation versus the introduced $\left[\mathrm{Pyr}_{2}\left[\mathrm{PdCl}_{4}\right] /\right.$ $\left([\mathrm{Pyr}]_{2}\left[\mathrm{PdCl}_{4}\right]+\mathrm{BmimPF}_{6}\right)$ molar fraction $(\mathrm{r})$ followed by ${ }^{1} \mathrm{H}$ NMR in deuterated dichloromethane (pyridinium moiety: ortho $(\bullet)$, meta $(\bullet)$ and para $(\boldsymbol{\Delta}), \mathrm{CH}$ in alpha position to the pyridinium moiety $(\diamond))$. For $r=0$ the same protons measured from $\mathrm{PyrPF}_{6}$ in $\mathrm{CD}_{2} \mathrm{Cl}_{2}$.

For $\mathrm{r}$ between 0 and 1 (these values correspond to $\mathrm{PyrPF}_{6}$ and $[\mathrm{Pyr}]_{2}\left[\mathrm{PdCl}_{4}\right]$ alone respectively), we observed intermediate signals between the pure compounds. This suggests that there was exchange between the cations of the salts and of the IL. Moreover, a temperature decrease down to $193 \mathrm{~K}$ did not lead to separation into two signals (see the supplementary material), in good agreement with a quick exchange. Lastly the non-linear fit suggests only partial exchange. It is to be noted that in the reaction conditions used, solvent was present in large excess so this would induce a shift in the equilibrium towards the complete exchange of the pyridinium cation. This behaviour was confirmed by FTIR study (Figure 8). 


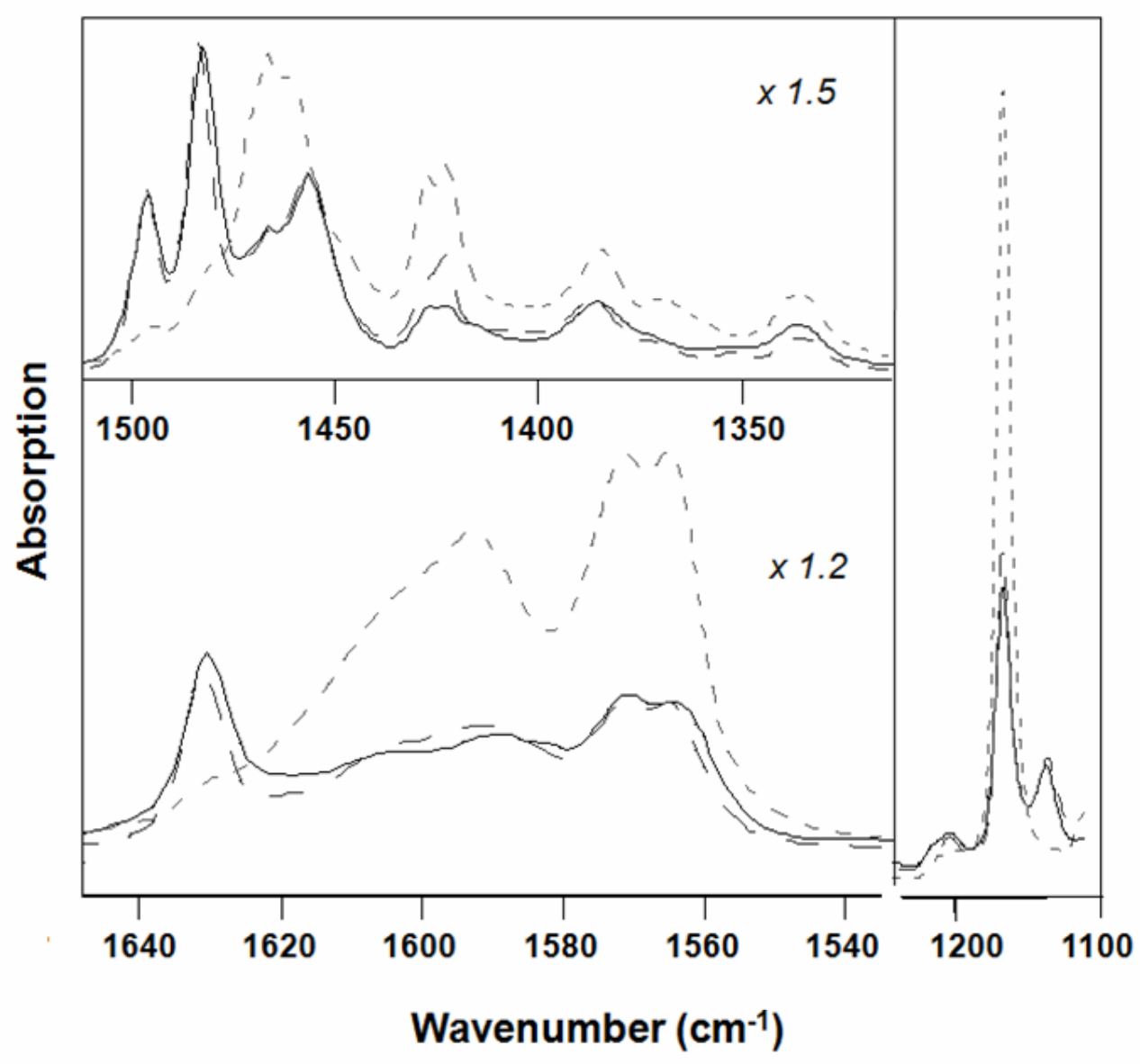

Figure 8. FTIR spectra in $\mathrm{CH}_{2} \mathrm{Cl}_{2}$ in $\mathrm{CaF}_{2}$ cell. The solid line shows the spectrum of the experimental mixture $[\mathrm{Pyr}]_{2}\left[\mathrm{PdCl}_{4}\right]$ and $\mathrm{BmimPF}_{6}(\mathrm{r}=0.28)$ and the wide dotted line the addition of spectra in $\mathrm{CH}_{2} \mathrm{Cl}_{2}$ of $\mathrm{PyrPF}_{6}$, $[\mathrm{Bmim}]_{2}\left[\mathrm{PdCl}_{4}\right]$ and $\mathrm{BmimPF}_{6}$, affected to the corrected factors leading to the best fit (close to the solid line). The top dotted curve plots the addition of those of $[\mathrm{Pyr}]_{2}\left[\mathrm{PdCl}_{4}\right]$ and of $\mathrm{BmimPF}_{6}$ in $\mathrm{CH}_{2} \mathrm{Cl}_{2}$ (corrected to obtain $\mathrm{r}=0.28$ ).

Indeed, the spectra of the mixture of $[\mathrm{Pyr}]_{2}\left[\mathrm{PdCl}_{4}\right]$ and $\mathrm{BmimPF} 6$ with $\mathrm{r}=0.28$ in $\mathrm{CH}_{2} \mathrm{Cl}_{2}$ shows typical absorption bands of $\operatorname{PyrPF}_{6}\left(1135,1482,1496\right.$ and $\left.1631 \mathrm{~cm}^{-1}\right)$ but also bands at 1167, 1563, 1571 and $1592 \mathrm{~cm}^{-1}$ corresponding to $\mathrm{BmimPF}_{6}$. In addition, using correction factors, we succeed in fitting the spectrum obtained for the mixture, with those of $\mathrm{PyrPF}_{6}$, [Bmim $]_{2}\left[\mathrm{PdCl}_{4}\right]$ and $\mathrm{BmimPF}_{6}$ in $\mathrm{CH}_{2} \mathrm{Cl}_{2}$. More, the spectra given by the addition of those of $[\mathrm{Pyr}]_{2}\left[\mathrm{PdCl}_{4}\right]$ and $\mathrm{BmimPF}_{6}$ for 0.28 molar fraction in palladate salt show different absorption bands (see supplementary material).

The peculiar stability of the NPs issued from salts from ionic liquids (compared to those issued from $\left.\mathrm{Pd}_{2}(\mathrm{dba})_{3}\right)$ in $\mathrm{BmimPF}_{6}$ can be attributed to the difference in chemical composition of the NP surface. When IL solvents are used as medium for the stabilization of NPs, Dupont et al. have suggested that imidazolium cations interact with the NP preferentially as aggregates (of 
cations and corresponding anions) rather than as isolated molecules. ${ }^{29}$. Here, $[\mathrm{Bmim}]_{2}\left[\mathrm{PdCl}_{4}\right]$ or $[\mathrm{Pyr}]_{2}\left[\mathrm{PdCl}_{4}\right]$ compounds can generate the presence of chlorine anions in the vicinity of the NP surface as well as $\mathrm{M}-\mathrm{Cl}$ linkage. So one could imagine that these anions are better involved than dba ligands in such aggregates and so can help stabilizing small NPs.

\section{Conclusions}

Imidazolium salt and pyridinium chiral salt: $[\mathrm{Bmim}]_{2}\left[\mathrm{PdCl}_{4}\right]$ and $[\mathrm{Pyr}]_{2}\left[\mathrm{PdCl}_{4}\right]$ were used for Heck reaction in ionic liquid. This reaction involved the formation of palladium nanoparticles which served as a reservoir of active species. Compared to traditional precatalysts, they lead to an enhanced catalytic efficiency and an improved recyclability. Indeed the use of palladate salts from ILs, that produce no by-products, provides better control of the formation and surface composition of the nanoparticles.

\section{Experimental Section}

General Procedures. All chemicals used were reagent grade. Ultrapure water was from a Millipore Milli-Q system (Milford, MA, USA). Iodobenzene (98\%), trans-stilbene (96\%), 2,3dihydrofuran $(\geq 99 \%)$ and styrene $(\geq 99 \%)$ were purchased from Sigma-Aldrich (Lyon, France). Styrene was kept in a brown glass bottle at $4^{\circ} \mathrm{C}$. Triethylamine $(99.98 \%)$ from Prolabo (Briare, France) was distilled over $\mathrm{KOH}$ then stored under nitrogen. Palladium catalyst tris(dibenzylideneacetone)dipalladium(0)chloroform adduct was obtained from Sigma-Aldrich (Lyon, France). Ionic liquid 1-butyl-3-methylimidazolium hexafluorophosphate $\left(\mathrm{BmimPF}_{6}\right)$ was purchased from Solvionic (Varilhes, France) and degassed under vacuum prior to use. The solvents diethylether $\left(\mathrm{Et}_{2} \mathrm{O}\right)$, dimethylformamide (DMF) and acetonitrile were HPLC grade and purchased from SDS (Paris, France). $\left[\mathrm{Bmim}_{2}\left[\mathrm{PdCl}_{4}\right]\right.$ was synthesized according to Dupont. ${ }^{22}$ $[\mathrm{Pyr}]_{2}\left[\mathrm{PdCl}_{4}\right]$ was prepared using the protocol given by Tourneux and al. ${ }^{23}$ The measurements of optical rotations were performed at $20^{\circ} \mathrm{C}$ in a Perkin-Elmer 241 Polarimeter (Na lamp, $\lambda=$ $589 \mathrm{~nm}$ ). Conversion percents of reactant and yields of reaction were determined by HPLC on a Waters Alliance 2695 HPLC system (Waters Corp., Milford, MA, USA) composed of a quaternary gradient pumping system with vacuum degasser. An autosampler system was used with a Waters 2487 dual wavelength absorbance detector or a 996 photodiode array detector (PDA) (Waters Corp., Milford, MA, USA). All measurements were realized at a single wavelength of $227 \mathrm{~nm}$ on a reverse-phase column XBridge Shield RP18, (2.1 x $100 \mathrm{~mm}), 3.5 \mu \mathrm{m}$ using isocratic conditions $60 / 40$ (acetonitrile $\left./ \mathrm{H}_{2} \mathrm{O}\right), 0.35 \mathrm{~cm}^{3} \cdot \mathrm{min}^{-1}$. GC analysis was performed on a Varian CP-3800 system equipped with a chiral capillary column (Cyclosil B from J\&W GC column) and a flame ionization detector set at $200{ }^{\circ} \mathrm{C}$. ${ }^{1} \mathrm{H}-$ and ${ }^{13} \mathrm{C}-\mathrm{NMR}$ analyses were conducted with Bruker Avance 300, 400 and $500 \mathrm{MHz}$ and chemical shifts are reported as parts 
per million (ppm). Infrared measurements were performed on Perkin-Elmer FTIR 1600. $\mathrm{CaF}_{2}$ cell thickness $67 \mu \mathrm{m}$. TEM measurements were made on a Jeol JEM - 2100 Transmission Electron Microscope operated at an accelerating voltage of $100 \mathrm{kV}$ on or a Hitachi HU12A TEM at an accelerating voltage of $75 \mathrm{kV}$. Samples in $\mathrm{BmimPF}_{6}(5 \mu \mathrm{L})$ for TEM analysis were diluted with a co-solvent, acetone $(600 \mu \mathrm{L})$, and a drop was placed on a copper grid covered by an ultrathin carbon film over a holey carbon film of 400 mesh. The mean particle size was determined using Image J software (http://rsb.info.nih.gov/ij/).

Synthesis of bis [(R)- or (S)- or (rac)-1-phenylethylpyridinium)] tetrachloropalladate $[\mathbf{P y r}]_{2}\left[\mathbf{P d C l}_{4}\right] .{ }^{23}$ Reaction of Zincke's salt ${ }^{30}$, readily obtained from pyridine and 1-chloro-2,4dinitrobenzene, with rac-1-phenylethylamine give 1-phenylethylpyridinium chloride. ${ }^{13} \mathrm{~A}$ mixture of 1-phenylethylpyridinium chloride $(500 \mathrm{mg}, 2.28 \mathrm{mmol})$ and palladium chloride $\mathrm{PdCl}_{2}$ $(202 \mathrm{mg}, 1.14 \mathrm{mmol})$ in acetonitrile $(75 \mathrm{~mL})$ was heated at reflux temperature for $24 \mathrm{~h}$. The orange solution formed was concentrated to $3 \mathrm{~mL}$ under reduced pressure. Addition of toluene $(25 \mathrm{~mL})$ afforded a yellow-orange solid that was recovered by filtration, washed with toluene (2 $\mathrm{x} 10 \mathrm{~mL}$ ), and dried in vacuum. Crystals were obtained by recrystallisation from acetonitrile solution at room temperature. ${ }^{1} \mathrm{H}-\mathrm{NMR}\left(500 \mathrm{MHz}, \mathrm{D}_{2} \mathrm{O}\right): \delta=2.06(\mathrm{~d}, \mathrm{~J}=7.0 \mathrm{~Hz}, 3 \mathrm{H}, \mathrm{CH} 3), 6.25$ (q, J = 7.0 Hz, 1H, CH), 7.40 (m, 5H, Ph), 7.94 (t, J = 7 Hz, 2H, m-py), 8.43 (t, J = 8 Hz, 1H, ppy), 8.84 (d, J = $7 \mathrm{~Hz}, 2 \mathrm{H}$, o-py) ppm; ${ }^{13} \mathrm{C}-\mathrm{NMR}\left(125 \mathrm{MHz}, \mathrm{D}_{2} \mathrm{O}\right): \delta=19.7(\mathrm{CH} 3), 70.7(\mathrm{CH})$, 127.5 (py C3), 128.3 (Ph C2'), 129.4 (Ph C4'), 129.8 (Ph C3'), 136.7 (Ph C1'), 143.1 (py C2), 145.9 (py C4) ppm. IR (KBr): 3434, 3040 (vC-H aromatic); 2972, 2929, 2870 (vC-H aliphatic); 1624, 1479, 1451, 1143, 698 cm-1. MS (ESI): Positive mode: 184 [pyr+]; Negative mode: 581 [Pyr] [ $\left.\mathrm{PdCl}_{3}\right]$-. Anal. Calc for $\mathrm{C}_{26} \mathrm{H}_{28} \mathrm{Cl}_{4} \mathrm{~N}_{2} \mathrm{Pd}: \mathrm{C}, 50.63 ; \mathrm{H}, 4.58 ; \mathrm{N}, 4.54$. Found: $\mathrm{C}, 50.73 ; \mathrm{H}$, 4.53; N, 4.87. Melting point: $155^{\circ} \mathrm{C} .[\alpha]_{\mathrm{D}}{ }^{20}$ bis $R-=+43,9^{\circ}$ and $[\alpha]_{\mathrm{D}}{ }^{20}$ bis $S-=-43,9^{\circ}(\mathrm{c} 1 \%$ $\mathrm{MeOH})$.

General procedure for catalytic Heck coupling in $\mathbf{B m i m P F}_{6}$. The reaction was performed according to the protocol described by Carmichael et al. ${ }^{8}$ A $50 \mathrm{~mL}$ flask containing a stirring bar was loaded with palladium catalyst $(10 \mu \mathrm{mol})$ and ionic liquid $\mathrm{BmimPF}_{6}\left(0.550 \mathrm{~g}, 0.4 \mathrm{~cm}^{3}\right)$ and stirred at room temperature during $5 \mathrm{~min}$. Then the reagents iodobenzene $(1 \mathrm{mmol})$, styrene $(1.2 \mathrm{mmol})$ and triethylamine $(1.5 \mathrm{mmol})$ were added and the flask quickly placed under reflux in an oil bath, and the homogeneous mixture stirred and heated for 1,3 or 6 hours at $100^{\circ} \mathrm{C}$. After cooling to ambient temperature, the organic reactants and products were extracted with diethylether $(7 \times 5 \mathrm{~mL})$ and the organic phase completed to $50 \mathrm{~mL}$. Extraction yields for transstilbene and iodobenzene $(98 \pm 1 \%)$ and also conversions and yields were determined by HPLC analysis. For recycling experiments, traces of remaining ether were removed from the previously obtained IL phase under vacuum. The IL phase was used directly without further treatment for the next run with iodobenzene $(1 \mathrm{mmol})$, styrene $(1.2 \mathrm{mmol})$ and triethylamine $(1.5 \mathrm{mmol})$ added again. The triethylamine hydrochloride formed during the reaction can be removed from the IL phase by washing with water to reduce the viscosity. 
General procedure for HPLC analysis. The different $50 \mathrm{~mL}$ organic phases were analysed by HPLC. Each sample was first filtered through a $0.2 \mu \mathrm{m}$ syringe filter (Nylon Acrodisc ${ }^{\circledR} 0.2 \mu \mathrm{m}$, Pall Corp., USA) and $10 \mu \mathrm{L}$ of the organic solutions diluted ten times were analysed. All the analyses were performed using the 2487 Waters detector, at a single wavelength of $227 \mathrm{~nm}$ on a reverse-phase column XBridge Shield RP18, (2.1 x $100 \mathrm{~mm}), 3.5 \mu \mathrm{m}$ using isocratic conditions $60 / 40$ (acetonitrile/ $\mathrm{H}_{2} \mathrm{O}$ ), $0.35 \mathrm{~cm}^{3} \cdot \mathrm{min}^{-1}$. Retention times were respectively $2.5,2.92$ and 4.28 min for iodobenzene, styrene and trans-stilbene. (see supplementary material).

Calibration curve. Several solutions of the reagents and product, were prepared in acetonitrile in order to obtain concentrations (from $1.034 .10^{-4}$ to $5.17 .10^{-6}$ mol. $\mathrm{L}^{-1}$ ). All solutions were stored in sealed vials, and $10 \mu \mathrm{L}$ of each solution was injected three times.

Formation of Pd nanoparticles. Palladium catalyst solutions were prepared by solubilisation in $\mathrm{BmimPF}_{6}(0.5 \mathrm{~g})$ of $\left[\mathrm{Bmim}_{2}\left[\mathrm{PdCl}_{4}\right](5.83 \mathrm{mg}, 0.0092 \mathrm{mmol})\right.$ or $[\mathrm{Pyr}]_{2}\left[\mathrm{PdCl}_{4}\right](5.6 \mathrm{mg}$, $0.0091 \mathrm{mmol})$. A borohydride - IL solution was prepared as followed: $\mathrm{NaBH}_{4}(13.60 \mathrm{mg}$, $0.36 \mathrm{mmol})$ was first dissolved in methanol $(200 \mu \mathrm{L}, 0.005 \mathrm{mmol})$ and at the end of the exothermic reaction, $0.8 \mathrm{~g}$ of $\mathrm{BmimPF}_{6}$ was added. This borohydride - IL solution was then placed in a drying cupboard at $40^{\circ} \mathrm{C}$ for 1 hour in order to remove methanol. The addition of $400 \mu \mathrm{L}$ of this solution on the previously prepared palladium catalyst solutions led to the formation of Pd NPs.

General procedure for catalytic Heck coupling in $\mathrm{BmimPF}_{6}$ with preformed NPs. After the formation of Pd NPs, the reagents (iodobenzene, styrene and triethylamine) were added and the reaction was performed at $100^{\circ} \mathrm{C}$ for 3 hours using the same protocol as described before.

Procedure for catalytic Heck coupling in $\mathrm{BmimPF}_{\mathbf{6}}$ with 2,3-dihydrofuran. A $50 \mathrm{~mL}$ flask containing a stirring bar was loaded with palladium catalyst $(10 \mu \mathrm{mol})$ and ionic liquid $\mathrm{BmimPF}_{6}$ $\left(0.550 \mathrm{~g}, 0.4 \mathrm{~cm}^{3}\right)$ and stirred at room temperature during $5 \mathrm{~min}$. Then the reagents iodobenzene (1 mmol), 2,3-dihydrofuran $(1.2 \mathrm{mmol})$ and triethylamine $(1.5 \mathrm{mmol})$ were added and the flask quickly placed under reflux in an oil bath, and the homogeneous mixture stirred and heated for 3 hours at $60^{\circ} \mathrm{C}$. After cooling to ambient temperature, the product was extracted with diethylether $(7 \times 5 \mathrm{~mL})$ and the organic phase evaporated under vacuum. NMR an GC analysis were in accordance with literature. ${ }^{28}$

\section{Acknowledgements}

Authors wish to thank the NMR service of the Federation of Molecular Chemistry of Toulouse, B. Payré and I. Fourquaux from CMEAB (Toulouse) and S.Balor and N.Benmeradi from IBCG (Toulouse) for TEM measurements; J.-C. Garrigues and C. Labau for HPLC measurements. 
Authors are indebted to Y. Génisson for helpful discussions and P. Winterton for English corrections.

\section{References}

1. Beletskaya, I. P.; Cheprakov, A. V. Chem. Rev. 2000, 100, 3009.

2. Tsuji, J. Palladium reagents and catalysts: new perspectives for the 21st century; WileyVCH, 2004, pp 670.

3. Zhang, R.; Sato, O.; Zhao, F. Y.; Sato, M.; Ikushima, Y. Chem. -Eur. J. 2004, 10, 1501.

4. Gordon, R. S.; Holmes, A. B. Chem. Commun. 2002, 640.

5. Moineau, J.; Pozzi, G.; Quici, S.; Sinou, D. Tetrahedron Lett. 1999, 40, 7683.

6. Dupont, J.; de Souza, R. F.; Suarez, P. A. Z. Chem. Rev. 2002, 102, 3667.

7. Olivier-Bourbigou, H.; Magna, L. J. Mol. Catal. A-Chem. 2002, 182-183, 419.

8. Carmichael, A. J.; Earle, M. J.; Holbrey, J. D.; McCormac, P. B.; Seddon, K. R. Org. Lett. 1999, 1, 997.

9. Calo, V.; Nacci, A.; Monopoli, A. J. Mol. Catal. A-Chem. 2004, 214, 45.

10. Giernoth, R. in In Situ Nmr Methods in Catalysis; Springer GmbH, 2007; Vol. 276, pp 1-23.

11. Jeffery, T.; David, M. Tetrahedron Lett. 1998, 39, 5751.

12. Zou, G.; Wang, Z. Y.; Zhu, J. R.; Tang, J.; He, M. Y. J. Mol. Catal. A-Chem.2003, 206, 193.

13. Patrascu, C.; Sugisaki, C.; Mingotaud, C.; Marty, J. D.; Genisson, Y.; Lauth-de Viguerie, N. Heterocycles 2004, 63, 2033.

14. Ross, J.; Chen, W. P.; Xu, L. J.; Xiao, J. L. Organometallics 2001, 20, 138.

15. Calo, V.; Nacci, A.; Monopoli, A.; Lopez, L.; di Cosmo, A. Tetrahedron 2001, 57, 6071.

16. Xu, L. J.; Chen, W. P.; Ross, J.; Xiao, J. L. Org. Lett. 2001, 3, 295.

17. Cassol, C. C.; Umpierre, A. P.; Machado, G.; Wolke, S. I.; Dupont, J. J. Am. Chem. Soc. 2005, 127, 3298.

18. de Vries, A. H. M.; Parlevliet, F. J.; Schmieder-van de Vondervoort, L.; Mommers, J. H. M.; Henderickx, H. J. W.; Walet, M. A. M.; de Vries, J. G. Adv. Synth. Catal. 2002, 344, 996.

19. Astruc, D. Inorg. Chem. 2007, 46, 1884.

20. Lin, I. J. B.; Vasam, C. S. J. Organomet. Chem. 2005, 690, 3498.

21. Itoh, H.; Naka, K.; Chujo, Y. J. Am. Chem. Soc. 2004, 126, 3026.

22. Dullius, J. E. L.; Suarez, P. A. Z.; Einloft, S.; de Souza, R. F.; Dupont, J.; Fischer, J.; De Cian, A. Organometallics 1998, 17, 815.

23. Tourneux, E.; Gornitzka, H.; Marty, J. D.; Viguerie, N. L. D. Molecules 2007, 12, 1940.

24. Bohm, V. P. W.; Herrmann, W. A. Chem. -Eur. J. 2000, 6, 1017.

25. Moisan, S.; Marty, J. D.; Cansell, F.; Aymonier, C. Chem. Commun. 2008, 12, 1428.

26. Schmidt, A. F.; Smirnov, V. V.; Al-Halaiga, A. Kinet. Catal. 2007, 48, 390. 
27. Prock1, S. S.; Kleist, W.; Gruber, M. A.; Kohler, K. Angew. Chem.,Int. Ed. 2004, 43, 1881.

28. Ozawa, F.; Kubo, A.; Matsumoto, Y.; Hayashi, T.; Nishioka, E.; Yanagi, K.; Moriguchi, K. Organometallics 1993, 12, 4188.

29. Migowski, P.; Machado, G.; Texeira, S. R.; Alves, M. C. M.; Morais, J.; Traverse, A.; Dupont, J. Phys. Chem. Chem. Phys., 2007, 9, 4814.

30. Zincke, T. Ann. Chem. 1903, 330, 361. 